\title{
Assessing the Impact of COVID-19 Pandemic on the Regions' Socio-Economic Development: The Case of Ukraine
}

\author{
By Pavlo Hryhoruk ${ }^{1}$, Nila Khrushch ${ }^{2}$, Svitlana Grygoruk ${ }^{3}$, Kateryna Gorbatiuk ${ }^{1}$, \\ Liudmyla Prystupa ${ }^{2}$
}

\begin{abstract}
Solving the problems of regional development belongs to the category of strategic and most important of each country. The COVID-19 pandemic has become the biggest challenge for the world economic system, causing a significant impact on the reduction of key macroeconomic indicators, changes in business conditions, which has raised the issue of assessing the social and economic development of regions. The paper considers the application of composite index assessment technology for the consequences of COVID-19 on the development indicators of Ukraine's regions. The comparison was conducted according to the data of the first two quarters of 2019 and 2020. For the study, eight indicators were selected, which by content feature were divided into a subset of economic indicators and a subset of social indicators. A partial composite development index was designed for each subset. The principal components method was used to calculate the weights of the components. The results of the analysis showed that the COVID-19 pandemic had a greater impact on economic development: for each region, there is a decrease in the value of the indicator. While for a partial composite index of social development such a decrease is less noticeable. The reflection of the regions in the space of these composite indices showed that their structure remained virtually unchanged. The analysis of the common composite index of regional development, designed by the convolution of partial composite indices indicators, also showed a decrease in its values in 2020. The paper analyses the measures taken by the Government of Ukraine to neutralize the effects of the pandemic.
\end{abstract}

Keywords: COVID-19 pandemic, socio-economic development, composite index, weighted additive convolution

\section{Problem Description}

The pandemic COVID-19 caused by SARS-CoV-2 proved to be the most unpleasant peacetime shock for the world economy in the current century. There is every reason to consider that from an economic point of view, this crisis will be deeper than in 2008-2009. At that time, the crisis was triggered by a demand shock from the spread of toxic financial assets around the world, while the current crisis is an unprecedented situation that is the result of a pandemic alone. The views of scientists, politicians, physicians on its duration, depth, consequences, and financial costs of their elimination are currently not unanimous. At the same time, human losses and economic damage are already evident, both for countries with developed economies and for those in developing

| ${ }^{1}$ Department of Automated Systems and Modeling in Economics, Khmelnytskyi National University, Khmelnytskyi, Ukraine

${ }^{2}$ Department of Finance, Banking and Insurance, Khmelnytskyi National University, Khmelnytskyi, Ukraine

${ }^{3}$ Department of Higher Mathematics and Computer Science, Khmelnytskyi National University,

Khmelnytskyi, Ukraine 
countries. Thus, according to calculations by the International Labor Organization (ILO), estimates of income losses indicate a global decline of 10.7 per cent during the first three quarters of 2020 (compared to the corresponding period in 2019), which amounts to USD 3.5 trillion, or 5.5 per cent of GDP for the first three quarters of 2019. Loss of income from work in countries with below-average incomes reached 15.1 per cent in lowermiddle-income countries and 11.4 per cent in upper-middle-income countries. The estimated total loss of working time in the second quarter of 2020 (relative to the fourth quarter of 2019) is now 17.3 per cent or 495 million full-time equivalent jobs. Countries most affected by below-average incomes, which are estimated to have reduced working hours by 23.3 per cent (near 240 million FTE jobs in the second quarter of the year) (ILO, 2020).

According to the World Bank (2020), the baseline forecast assumes a reduction in world GDP by 5.2 per cent in 2020 - the deepest global recession in decades, despite the extraordinary efforts of governments to counter it through fiscal and monetary policy. In the long run, the deep recessions caused by the pandemic will leave long-term scars due to declining investment, erosion of human capital due to job losses and training, and fragmentation of global trade and supply. According to forecasts, the developed economy will shrink by 7 per cent. This negative impact will also affect the prospects of developing countries, where the economic downturn will be 2.5 per cent.

The COVID-19 pandemic and severe restrictive measures aimed at preventing its spread have significantly affected the real business environment in Ukraine. As a result of the introduction of quarantine, the financial condition of large and medium-sized enterprises deteriorated, and a significant share of small enterprises ceased to operate. The main trends and problems of socio-economic development of regions in the context of national challenges caused by a pandemic presented in the State Strategy for Regional Development for 2021-2027 (CMU, 2020a), which was developed by the Cabinet of Ministers of Ukraine. It reflects forecasted key macroeconomic indicators for the end of 2020: falling GDP - 4.8 percent, inflation - 11.6 percent; unemployment rate -9.4 percent; fall in average wages -4.5 percent to 10.7 thousand hryvnias; fall in exports -5.5 percent, fall in imports - 10 percent. An even more pessimistic forecast for Ukraine's economic development is based on a study conducted by the German Economic Team (GET, Berlin) in collaboration with the Institute for Economic Research and Policy Consulting (IERPC, Kyiv). GDP will shrink by 7\% in 2020 as a result of the impact of external and internal shocks on the economy. Under the previous forecast, before the pandemic, GDP was expected to grow by $3 \%$. According to the pessimistic scenario, which envisages longer quarantine measures in Ukraine and stronger external shocks, the economic downturn will be 11.2 per cent (Ukrinform, 2020). However, according to the authors of the study, since Ukraine's economy was in good shape when the pandemic began, its impact will not be as strong as the impact of the crisis of 2009, which led to a reduction in GDP by 15 per cent. The government also has room in its policy to support the economy. Also important for overcoming the economic crisis are Ukraine's recent laws on the banking sector and the land market, as well as new IMF programs that will stabilize government spending.

To minimize the negative socio-economic consequences of the COVID-19 pandemic, it is necessary to assess existing trends, anticipate different scenarios for further development 
of the situation, carry out calculations to obtain data that will be the basis for rational science-based managerial decisions. These facts highlight the need for research to assess the real losses from the COVID-19 Pandemic in terms of regional socio-economic development, which will help identify weaknesses in national regional policy and contribute to the achievement of the goals reflected in the State Strategy for Regional Development for 2021-2027.

\section{Literature Review}

Despite the relatively short period of the COVID-19 pandemic spread, a significant amount of research has already been conducted to assess and overcoming its effects.

It should be noted that at the same time there is a lot of studies on the impact of previous pandemics on economic development, in particular, their influence on macroeconomic indicators of development. In particular, Cavallo, Galiani, Noy \& Pantano (2013), Bloom \& Canning (2004) emphasize the need to anticipate and manage future risks of pandemic spread. In paper (Jonung \& Roeger, 2006), based on the use of a quarterly macroeconomic model, estimates of GDP growth due to the pandemic in the EU in 2006 are given. The indirect economic impact of a pandemic based on general equilibrium models is presented in paper (Burns, Mensbrugghe \& Timmer, 2006). The study (Thomas et al., 2015) reflects the results of the evaluation of the impact of the Ebola epidemic on GDP reduction in West Africa's low-income countries. Although research on the impact of pandemics on economic development reflects declining macroeconomic indicators, the authors of these studies agreed that this is not likely to be a serious threat to global macroeconomics.

Scholars' assessments of the consequences of the COVID-19 pandemic are less optimistic. Although most of them agree that it is difficult to accurately estimate the duration, further spread, and consequences of the impact of negative processes on the development of regions today, the most optimistic forecasts predict a way out of the crisis only in a few years. Economic and mathematical modeling is an important tool for assessing current trends in the development of situations of such situations and predicting possible consequences. Grace Gondwe's study (2020) presents a macroeconomic model that assesses the possible effects of COVID-19 on African economies and provides forecasted indicators' values based on global scenarios. These estimates should not be taken as definitive predictions due to the focus on global shocks affecting trade between Africa and the rest of the world. All other direct effects of COVID-19 on productivity and government spending in Africa remain unchanged. Moreover, the presented analysis does not take into account domestic and multilateral measures used to mitigate the impact of COVID-19 on the African countries under study. The paper (Gallagher, 2020) on the example of Indonesia examines the direct impact of COVID-19 during the crisis on the indicators of total production, employment, and poverty. It also includes information on Indonesia's macroeconomic resilience and its ability to respond to the crisis using indicators like rapid inflation, volatile fiscal deficits, or rapid currency depreciation. The study presents three scenarios for GDP changes, taking into account the forecast published by the IMF: pessimistic, moderate, and optimistic ones. The author highlighted that results will help develop measures to improve the situation and prepare for post-crisis 
recovery. Al-Baidhani (2020) compared countries by level of social and economic development. To this end, the author used the Human Development Index (HDI), developed by the United Nations. The sample included countries both with developed and developing economies. The author also presents the sectors of the economy most affected by the pandemic in these countries, as well as estimates of GDP change. In the paper (Estrada, 2020), to assess the consequences of the pandemic, a new indicator "The Economic Uncontrolled Desgrowth from COVID-19" (- $\delta$ CO-VID-19), is proposed. It reflects the negative impact of the pandemic on GDP formation. The author presents the use of this indicator in the study of scenarios of world economic development and changes in global GDP and analyzes possible measures aimed at implementing these scenarios.

To highlight the consensus vision of future trends and objective assessment of risks and challenges facing the world economy, the Ministry for Development of Economy, Trade, and Agriculture of Ukraine, in cooperation with the UNICEF in Ukraine, prepared the Consensus Forecast entitled "Ukraine in 2020-2021: Aftermath of the Pandemic" (Nikolaichuk et.al., 2020) in which three scenarios of development of the domestic economy are given and the most probable forecast scenario for 2020-2021 is substantiated. It reflects the average values of the main forecast indicators of economic development of Ukraine, which are calculated as the median based on expert assessments of survey participants of leading experts in the field of macroeconomic analysis and forecasting. It should be noted that for values of GDP and unemployment, the differences between the studied development scenarios are not significant. At the same time, the estimates of the consumer price index differ quite significantly - according to the forecast based on a single scenario, they are higher, and the parameters of the exchange rate towards higher devaluation also differ, especially in 2021. At the same time, the average forecast is significantly closer in its parameters to the Government forecast, except for the USD exchange rate. We note, that the IMF forecast for the dynamics of GDP in Ukraine, which reflects the reduction of this indicator by the end of 2020 . by 8.2 per cent, is the most pessimistic among all comparable forecasts. Inflation parameters are as close as possible to the parameters of the consensus forecast.

To assess and identify structural imbalances in regional development, the use of a composite index is quite common. This approach is reflected, in particular, in publications (Rondinella \& Segre, 2014) (Mazziotta \& Pareto, 2015) (Gurna J \& Gurna K, 2015) (Meyer D., De Jongh \& Meyer N, 2016) (Meyer \& De Jongh, 2018) (Stanichkova \& Melecky, 2018) (De Jongh \& Meyer, 2019) (Hryhoruk, Khrushch \& Grygoruk, 2019a) (Hryhoruk, Khrushch \& Grygoruk, 2020) (Royuela, 2020). However, its application to assess the effects of a pandemic in recent studies has received insufficient attention. The results of the analysis show that most studies reflect rapid assessments of the socio-economic impacts of COVID-19 with an emphasis on trends and potential scenarios and are mainly focused on assessing GDP change as one of the most important macroeconomic indicators. At the same time, research at the level of assessing changes in development trends in individual regions of the country is practically not presented. Our study aims to develop an approach to the analysis of the impact of COVID-19 on the level and structure of socio-economic development of the regions of Ukraine, through the use of composite index assessment technology, principal components method, and graphical data visualization. We use composite indices to comprehensively assess the impact of the 
pandemic on the regions' socio-economic development and the change in the structuring of regions concerning these indicators. We use the principal components method to determine the weight of each initial indicator when designing composite indices.

\section{Research Methodology}

The composite (comprehensive) index assessment technology is aimed at reducing the indicator space of the studied phenomenon to describe it more compactly. The studied characteristic, which often has the form of latent quality, which is not subject to direct measurement and description, is usually described by some set of measured indicators. A fairly common approach is when the assessment is based on a complete reduction of the initial set of indicators. That is, the final result of calculations is a single composite (comprehensive) index, which accumulates all the information contained in the original set of indicators. This simplifies the further interpretation of the results.

When designing a composite index, the following requirements must be taken into account:

- change of its positive quality should correspond to the directions of "advantage" of its components;

- the composite index should take into account the informativeness of all its components and at the same time allow the compression of redundant information contained in them;

- it should reproduce as much as possible the variation of partial indicators based on which it is designed;

- the importance of each partial indicator must be taken into account;

- weights for its components must be statistically significant.

For correct use and clear interpretation of the results it is necessary, that the composite index had the following properties:

- spatial comparability, i.e. the possibility of comparing the index values for different objects under study;

- differentiating ability, i.e. it must be sufficiently informative and provide an opportunity to distinguish between individual objects of the initial data set;

- the simplicity of interpretation, i.e. the result must have a clear, understandable and clear interpretation;

To ensure the above requirements for the composite index designing procedure, the initial indicators $X=\left\{X_{1}, X_{2}, \ldots, X_{n}\right\}$ should be presented in the form of stimulants. This will provide a positive correlation with the characteristic under study. The removal of the influence of units of measurement is achieved by normalizing the values of the initial indicators, usually by reducing their values from 0 to 1 . These requirements are provided by using the transformation (Hryhoruk, Khrushch \& Grygoruk, 2019b):

$u_{i j}=1-\frac{\left|x_{i j}-x_{j}^{*}\right|}{x_{j \max }-x_{j \min }}$,

where $u_{i j}$ - are normalized values of indicators; $x_{i j}$ - are initial values of indicator $X_{j}$; 
$x_{j \min }=\min _{i} x_{i j}, \quad x_{j \max }=\max _{i} x_{i j} \quad x_{j}^{*}=\left\{\begin{array}{l}x_{j \max }, \quad \text { when } X_{j} \text { is a incentive; } \\ x_{j \min }, \quad \text { when } X_{j} \text { is a disincentive; } ; i=1 . . m,\end{array}\right.$ $j=1 . . n ; m-$ is the number of objects under study (in this case - regions); $n-$ is the number of initial indicators.

In cases where the indicators $X_{j}$ are relative indicators of the dynamics, the transformation should be carried out according to the formula:

$u_{i j}= \begin{cases}\frac{x_{i j}}{x_{j \max }}, & \text { when } X_{j} \text { is a incentive; } \\ \frac{x_{j \min }}{x_{i j}}, & \text { when } X_{j} \text { is a disincentive; }\end{cases}$

The procedure of data normalization can be carried out according to other rules, depending on the origin of the indicator.

A weighted additive or multiplicative convolution is used as the synthesizing function $Q$ to determine the value of the composite index:

$$
\begin{aligned}
& Q_{A i}=\sum_{j=1}^{n} w_{j} u_{i j}, \\
& Q_{M i}=\prod_{j=1}^{n} u_{i j}^{w_{j}},
\end{aligned}
$$

where $Q_{A i}, Q_{M i}$ - are the values of the composite index for additive and multiplicative convolution respectively; $w_{j}$ are weight coefficient values for initial indicators; $j=1 . . n$, $i=1 . . m$.

The weight coefficients should meet the condition:

$$
\sum_{j=1}^{n} w_{j}=1
$$

The use of formulas (1), (2), (5) provides the composite index values in the range [0;1]. If the initial values of $X_{j}$ are values measured on an absolute scale, then, in our opinion, it is advisable to use additive convolution. If the initial indicators are relative indicators of dynamics, then it is advisable to use a multiplicative convolution. Therefore, in the case when among the selected indicators are both absolute and relative measured, it is proposed to use block convolution by the formula:

$$
Q_{i}=w_{A} Q_{A i}+w_{M} Q_{M i},
$$

where $Q_{i}$ - is a result value of composite index; $Q_{A i}-$ is a value of the partial composite index, that is calculated by the formula (3) using the indicators measured by absolute scale; $Q_{M i}$ - is a value of the partial composite index, that is calculated by the formula (4) using the indicators measured by the relative dynamic scale; $w_{A}, w_{M}-$ are weighted coefficients of partial composite indices; $i=1 . . n$.

When choosing the set of initial indicators, it should be borne in mind that the presence of a large number of them complicates the composite index designing procedure, 
negatively affects the significance of weight coefficients, and, consequently, reduces its informativeness and discriminatory ability. In this case, it is advisable to divide the set of initial indicators into groups, each of which reflects a certain property of the studied characteristic. For each group, it is necessary to calculate its partial composite index using one of the formulas (3), (4), and formulas (6) for the final result if is needed. The common composite index is calculated by the formula:

$Q_{\text {COMi }}=\sum_{s=1}^{k} v_{s} Q_{s i}$

where $Q_{C O M}$ - are the values of common composite index; $Q_{s i}$ - are values of partial composite indexes for groups of initial indicators; $v_{s}$ - are weight coefficient values for partial composite indexes; they should meet the condition like the formula (5); $k-$ is a number of groups.

Determining the weight coefficients for both the set of initial indicators and for partial composite indices in the case of group convolution is a non-trivial task. Quite common is the approach in which all components of the composite index are equal. This approach simplifies the calculations but enhances the effects of compensation when the high values of some indicators are offset by the low values of others. Another approach is to use the results of an expert survey to establish weights. We use an approach based on the application of methods of multidimensional statistical analysis, in particular, the principal components method. The weights are determined in proportion to the absolute values of the factor loadings of the first principal component:

$$
w_{j}=\frac{f_{j 1}}{\sum_{i=1}^{n} f_{i 1}} \text {, }
$$

where $f_{j 1}-$ are values of first principal component's factor loadings, $j=1 . . n$.

Identifying the weights of partial composite indices can be done in proportion to the number of initial indicators included in each group:

$v_{j}=\frac{n_{j}}{n}$,

where $n_{j}-$ is a number of initial indicators in a $j$-th group, $j=1 . . k$.

In our study, we use the described above approaches to identify the weight coefficients.

\section{Results and Discussion}

Let us assess changes in the socio-economic development of Ukraine's regions due to the impact of the COVID-19 pandemic. As initial indicators, we chose two groups of indicators. The first reflects the economic component of regional development, the second - social one. The information source for the calculations was the data of the State Statistics Service of Ukraine (SSSU, 2019) (SSSU, 2020) and the Ministry for Communities and Territories Development of Ukraine (MCTDU, 2020). To achieve the possibility of comparing the results, we chose the first two quarters of 2019 (pre-quarantine period) and the first two quarters of 2020 (the period of the COVID-19 pandemic) as the periods for 
the calculations. As initial indicators, we chose such.

For a group of indicators of economic development: $X_{E 1}$ - Volume of sold industrial products per capita, UAH; $X_{E 2}-$ Volume of agricultural production per capita of the rural population, UAH; $X_{E 3}-$ Volume of construction works performed per capita, UAH; $X_{E 4}$ - Volume of capital investments per capita cumulatively since the beginning of the year, UAH; $X_{E 5}-$ Exports of goods per capita, USD.

For a group of indicators of social development: $X_{S 1}$ - Unemployment rate of the population; $X_{S 2}-$ Employment rate of the population; $X_{S 3}-$ The volume of housing commissioned per 10 thousand people, sq. meters of total area.

It should be noted that the GRP per capita indicator is quite representative and important for the analysis of the socio-economic development of the regions, but at the time of preparation of this article statistics for this indicator for the first two quarters of 2020 aren't available.

For compact use of Ukraine regions' names, we assigned to each of them the corresponding code which we used further for the designation of each region (Table 1).

Table 1: Correspondence between the name of the region of Ukraine and its code designation

\begin{tabular}{|c|l|c|l|}
\hline Code & Region & Code & Region \\
\hline r_1 & Vinnytsya & r_13 & Mykolayiv \\
\hline r_2 & Volyn & r_14 & Odesa \\
\hline r_3 & Dnipropetrovsk & r_15 & Poltava \\
\hline r_4 & Donetsk & r_16 & Rivne \\
\hline r_5 & Zhytomyr & r_17 & Sumy \\
\hline r_6 & Zakarpattya & r_18 & Ternopil \\
\hline r_7 & Zaporizhzhya & r_19 & Kharkiv \\
\hline r_8 & Ivano-Frankivsk & r_20 & Kherson \\
\hline r_9 & Kyiv & r_21 & Khmelnytskiy \\
\hline r_10 & Kirovohrad & r_22 & Cherkasy \\
\hline r_11 & Luhansk & r_23 & Chernivtsi \\
\hline r_12 & Lviv & r_24 & Chernihiv \\
\hline
\end{tabular}

The values of initial indicators for calculations are shown in tables 2 and 3 . To simplify the display of data in the tables, the corresponding period is denoted only by a year, bearing in mind that real data reflect the values of indicators only for the first two quarters of the appropriate year.

Table 2: The values of initial indicators that reflect economic development

\begin{tabular}{|c|c|c|c|c|c|c|c|c|c|c|}
\hline \multirow{2}{*}{ Code } & \multicolumn{2}{|c|}{$\boldsymbol{X}_{\boldsymbol{E} 1}$} & \multicolumn{2}{c|}{$\boldsymbol{X}_{\boldsymbol{E} 2}$} & \multicolumn{2}{c|}{$\boldsymbol{X}_{\boldsymbol{E}}$} & \multicolumn{2}{c|}{$\boldsymbol{X}_{\boldsymbol{E} 4}$} & \multicolumn{2}{c|}{$\boldsymbol{X}_{\boldsymbol{E}}$} \\
\cline { 2 - 11 } & $\mathbf{2 0 1 9}$ & $\mathbf{2 0 2 0}$ & $\mathbf{2 0 1 9}$ & $\mathbf{2 0 2 0}$ & $\mathbf{2 0 1 9}$ & $\mathbf{2 0 2 0}$ & $\mathbf{2 0 1 9}$ & $\mathbf{2 0 2 0}$ & $\mathbf{2 0 1 9}$ & $\mathbf{2 0 2 0}$ \\
\hline r_1 & 27000.4 & 24591.1 & 11985.0 & 12393.0 & 2374.5 & 1817.6 & 3676.8 & 2843.3 & 469.1 & 489.0 \\
\hline r_2 & 15214.0 & 13375.4 & 5497.0 & 5373.0 & 725.6 & 671.2 & 5259.8 & 5600.9 & 312.3 & 273.7 \\
\hline r_3 & 77223.1 & 61798.1 & 15750.0 & 11410.0 & 2631.0 & 2288.4 & 8503.2 & 6518.8 & 1314.7 & 1166.0 \\
\hline r_4 & 36731.0 & 28602.3 & 9258.0 & 7143.0 & 511.7 & 562.4 & 2636.2 & 1999.5 & 549.8 & 450.1 \\
\hline r_5 & 19059.7 & 17143.6 & 6380.0 & 6338.0 & 739.0 & 534.9 & 2102.7 & 1673.9 & 299.2 & 256.5 \\
\hline r_6 & 10320.5 & 8751.2 & 2418.0 & 2686.0 & 634.3 & 435.0 & 1952.2 & 1245.7 & 618.2 & 476.0 \\
\hline
\end{tabular}




\begin{tabular}{|c|c|c|c|c|c|c|c|c|c|c|}
\hline \multirow{2}{*}{ Code } & \multicolumn{2}{|c|}{$\boldsymbol{X}_{\boldsymbol{~} 1}$} & \multicolumn{2}{c|}{$\boldsymbol{X}_{\boldsymbol{L}}$} & \multicolumn{2}{c|}{$\boldsymbol{X}_{\boldsymbol{E}}$} & \multicolumn{2}{c|}{$\boldsymbol{X}_{\boldsymbol{~}}$} & \multicolumn{2}{c|}{$\boldsymbol{X}_{\boldsymbol{~}}$} \\
\cline { 2 - 11 } & $\mathbf{2 0 1 9}$ & $\mathbf{2 0 2 0}$ & $\mathbf{2 0 1 9}$ & $\mathbf{2 0 2 0}$ & $\mathbf{2 0 1 9}$ & $\mathbf{2 0 2 0}$ & $\mathbf{2 0 1 9}$ & $\mathbf{2 0 2 0}$ & $\mathbf{2 0 1 9}$ & $\mathbf{2 0 2 0}$ \\
\hline r_7 & 58291.4 & 51597.1 & 17781.0 & 8528.0 & 946.1 & 604.2 & 3242.9 & 2353.7 & 887.6 & 847.1 \\
\hline r_8 & 25095.2 & 18584.7 & 3436.0 & 3456.0 & 901.1 & 806.8 & 2555.6 & 1449.9 & 320.8 & 249.5 \\
\hline r_9 & 33417.0 & 31227.4 & 9430.0 & 9121.0 & 2049.4 & 2540.0 & 9860.3 & 6055.3 & 547.6 & 496.0 \\
\hline r_10 & 16666.8 & 17513.4 & 7845.0 & 6192.0 & 875.3 & 556.2 & 2430.5 & 2518.3 & 344.9 & 497.8 \\
\hline r_11 & 5707.2 & 3976.3 & 2951.0 & 2130.0 & 94.8 & 86.4 & 523.3 & 322.5 & 41.6 & 28.7 \\
\hline r_12 & 20815.2 & 19269.3 & 4090.0 & 3822.0 & 1661.5 & 1663.5 & 4068.8 & 2431.1 & 414.6 & 405.2 \\
\hline r_13 & 27525.0 & 26909.4 & 15583.0 & 7572.0 & 1264.4 & 1140.7 & 4539.7 & 2413.4 & 901.1 & 751.6 \\
\hline r_14 & 12697.2 & 12929.8 & 7999.0 & 2658.0 & 2484.3 & 2790.8 & 3371.3 & 2564.4 & 280.9 & 258.2 \\
\hline r_15 & 65034.2 & 52739.4 & 7136.0 & 6493.0 & 2340.3 & 2374.2 & 6108.9 & 4930.4 & 739.8 & 821.4 \\
\hline r_16 & 18201.7 & 19042.5 & 4236.0 & 4081.0 & 755.2 & 757.5 & 2185.7 & 1280.9 & 179.6 & 185.2 \\
\hline r_17 & 22444.0 & 20581.6 & 5821.0 & 5736.0 & 560.0 & 539.9 & 2640.3 & 1702.8 & 377.5 & 395.5 \\
\hline r_18 & 9875.6 & 8656.1 & 4226.0 & 4207.0 & 818.3 & 798.5 & 3384.7 & 2108.4 & 203.5 & 181.7 \\
\hline r_19 & 36238.2 & 30226.5 & 8363.0 & 6636.0 & 2398.1 & 2159.1 & 3086.1 & 2346.2 & 229.8 & 244.4 \\
\hline r_20 & 14805.0 & 15222.2 & 19755.0 & 15379.0 & 638.2 & 519.8 & 4240.3 & 1251.8 & 128.5 & 131.8 \\
\hline r_21 & 17275.6 & 17353.3 & 6166.0 & 6123.0 & 1106.0 & 1189.1 & 3214.1 & 2601.7 & 229.8 & 222.3 \\
\hline r_22 & 30927.6 & 29332.4 & 12731.0 & 12514.0 & 596.5 & 578.0 & 3095.9 & 2153.8 & 339.5 & 375.0 \\
\hline r_23 & 8143.7 & 6881.8 & 3135.0 & 3093.0 & 776.7 & 777.6 & 1563.2 & 926.7 & 116.4 & 76.8 \\
\hline r_24 & 16876.2 & 15324.2 & 5829.0 & 5499.0 & 655.0 & 916.2 & 3071.5 & 2301.8 & 374.5 & 384.6 \\
\hline
\end{tabular}

Table 3: The values of initial indicators that reflect social development

\begin{tabular}{|c|c|c|c|c|c|c|}
\hline \multirow{2}{*}{ Code } & \multicolumn{2}{|c|}{$\boldsymbol{X}_{\boldsymbol{S 1}}$} & \multicolumn{2}{c|}{$\boldsymbol{X}_{\boldsymbol{S}}$} & \multicolumn{2}{c|}{$\boldsymbol{X}_{\boldsymbol{S 3}}$} \\
\cline { 2 - 7 } & $\mathbf{2 0 1 9}$ & $\mathbf{2 0 2 0}$ & $\mathbf{2 0 1 9}$ & $\mathbf{2 0 2 0}$ & $\mathbf{2 0 1 9}$ & $\mathbf{2 0 2 0}$ \\
\hline r_1 & 10.3 & 10.4 & 57.1 & 56.9 & 829.7 & 720.5 \\
\hline r_2 & 12.3 & 12.3 & 49.5 & 49.2 & 2216.1 & 1806.3 \\
\hline r_3 & 8.1 & 8.2 & 59.0 & 58.4 & 551.8 & 235.0 \\
\hline r_4 & 14.1 & 14.5 & 50.6 & 49.8 & 64.8 & 45.5 \\
\hline r_5 & 10.5 & 10.5 & 55.4 & 55.8 & 774.3 & 438.6 \\
\hline r_6 & 9.6 & 10.2 & 54.7 & 54.3 & 1927.4 & 1430.0 \\
\hline r_7 & 10.2 & 10.4 & 57.0 & 56.5 & 256.1 & 150.0 \\
\hline r_8 & 8.0 & 8.1 & 55.5 & 54.4 & 3144.1 & 1833.7 \\
\hline r_9 & 6.3 & 6.6 & 58.7 & 58.2 & 3898.2 & 3932.9 \\
\hline r_10 & 12.1 & 12.3 & 54.9 & 54.2 & 413.5 & 231.0 \\
\hline r_11 & 15.3 & 15.2 & 57.0 & 57.3 & 41.9 & 51.0 \\
\hline r_12 & 7.4 & 7.4 & 56.9 & 56.2 & 2524.2 & 1734.9 \\
\hline r_13 & 10.0 & 10.3 & 58.5 & 57.9 & 333.0 & 205.1 \\
\hline r_14 & 7.0 & 6.9 & 57.2 & 57.0 & 2003.0 & 1391.7 \\
\hline r_15 & 11.8 & 11.7 & 55.6 & 55.2 & 679.7 & 457.1 \\
\hline r_16 & 9.8 & 9.1 & 57.0 & 56.7 & 1366.6 & 1080.6 \\
\hline r_17 & 9.1 & 9.1 & 56.8 & 57.2 & 386.8 & 282.9 \\
\hline r_18 & 11.8 & 11.3 & 52.2 & 52.1 & 1908.0 & 1543.0 \\
\hline r_19 & 5.9 & 5.8 & 61.4 & 60.8 & 486.1 & 870.3 \\
\hline r_20 & 11.3 & 11.1 & 57.3 & 57.2 & 566.3 & 355.6 \\
\hline r_21 & 9.8 & 9.5 & 55.1 & 55.3 & 1078.3 & 1069.1 \\
\hline r_22 & 9.7 & 9.3 & 57.7 & 57.6 & 601.5 & 398.9 \\
\hline r_23 & 8.2 & 8.6 & 57.3 & 57.2 & 2996.0 & 1670.9 \\
\hline r_24 & 10.7 & 11.5 & 57.0 & 56.8 & 637.5 & 577.4 \\
\hline & & & & & & \\
\hline
\end{tabular}


Next step, we normalized the data. For a more objective comparison of the results of calculations when performing this procedure, the data for 2019 and 2020 for each indicator we combined into one sample. This allowed adequate tracking changes in the value of the calculated composite index. Considering, that all data are indicators, measured on an absolute scale, the normalization procedure has performed by formula (1). Note that $X_{S 1}$ is a disincentive. and the other indicators in both groups-stimulants.

To obtain the weight coefficients of the initial indicators for each group, we calculated the correlation matrices. The results of the calculations are shown in Tables 4 and 5 . Note that in this case, we also combined the values of the indicators for two time periods in one sample, and thus obtained one correlation matrix for each group of indicators

Table 4: The values of correlation matrixes for economic indicators

\begin{tabular}{|c|c|c|c|c|c|}
\hline Indices & $\boldsymbol{X}_{\boldsymbol{E} 1}$ & $\boldsymbol{X}_{\boldsymbol{E} 2}$ & $\boldsymbol{X}_{\boldsymbol{E} \mathbf{3}}$ & $\boldsymbol{X}_{\boldsymbol{E} 4}$ & $\boldsymbol{X}_{\boldsymbol{E} \mathbf{5}}$ \\
\hline$X_{E 1}$ & 1.0000 & 0.5231 & 0.5097 & 0.6037 & 0.8330 \\
\hline$X_{E 2}$ & 0.5231 & 1.0000 & 0.2048 & 0.4141 & 0.4503 \\
\hline$X_{E 3}$ & 0.5097 & 0.2048 & 1.0000 & 0.6082 & 0.4158 \\
\hline$X_{E 4}$ & 0.6037 & 0.4141 & 0.6082 & 1.0000 & 0.5859 \\
\hline$X_{E 5}$ & 0.8330 & 0.4503 & 0.4158 & 0.5859 & 1.0000 \\
\hline
\end{tabular}

Table 5: The values of correlation matrixes for social indicators

\begin{tabular}{|c|c|c|c|}
\hline Indices & $X_{S 1}$ & $X_{S 2}$ & $X_{S 3}$ \\
\hline$X_{S 1}$ & 1.0000 & -0.5962 & -0.5096 \\
\hline$X_{S 2}$ & -0.5962 & 1.0000 & -0.0606 \\
\hline$X_{S 3}$ & -0.5096 & -0.0606 & 1.0000 \\
\hline
\end{tabular}

The calculated values of the factor loadings of the first principal component for the corresponding group of indicators and obtained by them the values of the weight coefficients calculated by the formula (8) are given in Tables 6, 7 .

Table 6: The values of factor loadings and appropriate weight coefficients for economic indicators

\begin{tabular}{|c|c|c|}
\hline Indices & Factor loadings $\boldsymbol{f}_{\boldsymbol{j} 1}$ & Weight coefficients $\boldsymbol{w}_{\boldsymbol{j}}$ \\
\hline $\boldsymbol{X}_{\boldsymbol{E} 1}$ & 0.90 & 0.23 \\
\hline $\boldsymbol{X}_{\boldsymbol{E} 2}$ & 0.64 & 0.16 \\
\hline $\boldsymbol{X}_{\boldsymbol{E} 3}$ & 0.69 & 0.18 \\
\hline $\boldsymbol{X}_{\boldsymbol{E} 4}$ & 0.82 & 0.21 \\
\hline $\boldsymbol{X}_{\boldsymbol{E} 5}$ & 0.86 & 0.22 \\
\hline
\end{tabular}

Table 7: The values of factor loadings and appropriate weight coefficients for social indicators

\begin{tabular}{|c|c|c|}
\hline Indices & Factor loadings $\boldsymbol{f}_{\boldsymbol{j} 1}$ & Weight coefficients $\boldsymbol{w}_{\boldsymbol{j}}$ \\
\hline $\boldsymbol{X}_{\boldsymbol{S} 1}$ & 0.95 & 0.43 \\
\hline $\boldsymbol{X}_{\boldsymbol{S} \mathbf{2}}$ & 0.70 & 0.31 \\
\hline $\boldsymbol{X}_{\boldsymbol{S} 3}$ & 0.60 & 0.26 \\
\hline
\end{tabular}

Next step, we calculated the values of the partial composite indices Q1 and $Q^{2}$ and the 
common composite index $Q_{\text {СОм. }}$. To reach this aim, we used the formula of linear weighted additive convolution (6) to calculate partial composite indices, and formula (7) to calculate the values of the common composite index. The corresponding weight coefficients were calculated by the formula (9). The results of the calculations are listed in Table 8.

Table 8: The values of partial composite indices and common composite index

\begin{tabular}{|c|c|c|c|c|c|c|}
\hline \multirow{2}{*}{ Code } & \multicolumn{3}{|c|}{$\mathbf{2 0 1 9}$} & \multicolumn{3}{c|}{$\mathbf{2 0 2 0}$} \\
\cline { 2 - 7 } & $\boldsymbol{Q}_{E}$ & $\boldsymbol{Q}_{\boldsymbol{S}}$ & $\boldsymbol{Q}_{\boldsymbol{C O M}}$ & $\boldsymbol{Q}_{\boldsymbol{E}}$ & $\boldsymbol{Q}_{\boldsymbol{S}}$ & $\boldsymbol{Q}_{\boldsymbol{C O M}}$ \\
\hline r_1 & 0.46 & 0.48 & 0.47 & 0.33 & 0.46 & 0.38 \\
\hline r_2 & 0.22 & 0.29 & 0.24 & 0.21 & 0.25 & 0.23 \\
\hline r_3 & 0.70 & 0.61 & 0.67 & 0.55 & 0.57 & 0.56 \\
\hline r_4 & 0.25 & 0.09 & 0.19 & 0.19 & 0.05 & 0.14 \\
\hline r_5 & 0.17 & 0.42 & 0.26 & 0.14 & 0.41 & 0.24 \\
\hline r_6 & 0.09 & 0.52 & 0.26 & 0.06 & 0.45 & 0.21 \\
\hline r_7 & 0.44 & 0.44 & 0.44 & 0.29 & 0.42 & 0.34 \\
\hline r_8 & 0.18 & 0.70 & 0.37 & 0.13 & 0.58 & 0.30 \\
\hline r_9 & 0.50 & 0.91 & 0.65 & 0.44 & 0.88 & 0.60 \\
\hline r_10 & 0.19 & 0.32 & 0.24 & 0.16 & 0.28 & 0.20 \\
\hline r_11 & 0.02 & 0.20 & 0.09 & 0.00 & 0.21 & 0.08 \\
\hline r_12 & 0.26 & 0.72 & 0.43 & 0.21 & 0.65 & 0.38 \\
\hline r_13 & 0.37 & 0.50 & 0.42 & 0.24 & 0.46 & 0.32 \\
\hline r_14 & 0.31 & 0.71 & 0.46 & 0.26 & 0.67 & 0.41 \\
\hline r_15 & 0.51 & 0.36 & 0.46 & 0.44 & 0.34 & 0.41 \\
\hline r_16 & 0.15 & 0.54 & 0.29 & 0.13 & 0.54 & 0.28 \\
\hline r_17 & 0.17 & 0.50 & 0.30 & 0.15 & 0.50 & 0.28 \\
\hline r_18 & 0.15 & 0.36 & 0.23 & 0.12 & 0.35 & 0.21 \\
\hline r_19 & 0.37 & 0.77 & 0.52 & 0.30 & 0.78 & 0.48 \\
\hline r_20 & 0.32 & 0.42 & 0.36 & 0.21 & 0.42 & 0.29 \\
\hline r_21 & 0.21 & 0.47 & 0.31 & 0.20 & 0.49 & 0.31 \\
\hline r_22 & 0.28 & 0.51 & 0.36 & 0.25 & 0.51 & 0.35 \\
\hline r_23 & 0.09 & 0.72 & 0.33 & 0.08 & 0.62 & 0.28 \\
\hline r_24 & 0.17 & 0.45 & 0.28 & 0.16 & 0.40 & 0.25 \\
\hline
\end{tabular}

Let's compare the values of partial composite indices for the first two quarters of 2019 and the corresponding period of 2020. To do this, we considered the graphical interpretation of the results (Figures 1,2). According to the analysis of the presented figures, there are changes in the socio-economic development of regions during the study period. The values of the indices for 2020 are less than the corresponding values for 2019. Therefore, we can state that the COVID-19 pandemic harmed the socio-economic development of each region of Ukraine. According to the results of January-June 2020, as a whole, there were negative trends in the dynamics of production in key areas of development: industry, agriculture, construction, and capital investment, for most Ukraine's regions. This fact was evidenced by the main socio-economic indicators presented in Table 2. The decrease in our calculated partial composite index of economic development is especially noticeable for Vinnytsya (r_1), Dnipropetrovsk (r_3), Zaporizhya (r_7), Mykolayiv (r_13), and Kherson (r_20) regions, which is explained by a significant decrease in the values of baseline indicators that 
were used for calculation appropriate patrial index. In particular, a significant decrease in industrial production was observed in Dnipropetrovsk (-17.6 per cent) and Zaporizhya (11.4 per cent) oblasts, which are historically industrial centers of Ukraine. In January-June 2020, the volume of gross agricultural production per capita decreased the most in Odesa (by 66.8 per cent), Zaporizhya (by 52.0 per cent), Mykolayiv (by 51.4 per cent), Dnipropetrovsk (by 27.6 per cent), Kherson (by 22.2 per cent) regions. For the partial composite index of social development, the largest decrease for its values was for IvanoFrankivsk ( $r \_8$ ) and Chernivtsi regions ( $\left.r \_23\right)$. This is since these regions were the first, where strict quarantine restrictions were introduced, which harmed the indicators of social development selected for analysis. At the same time, for most regions, the value of this index has either not changed or is insignificant, and for Luhansk (r_11), Kharkiv ( $\left.r \_19\right)$, and Khmelnytskyi ( $\left.r \_21\right)$ regions there is a slight increase in the values of this index.

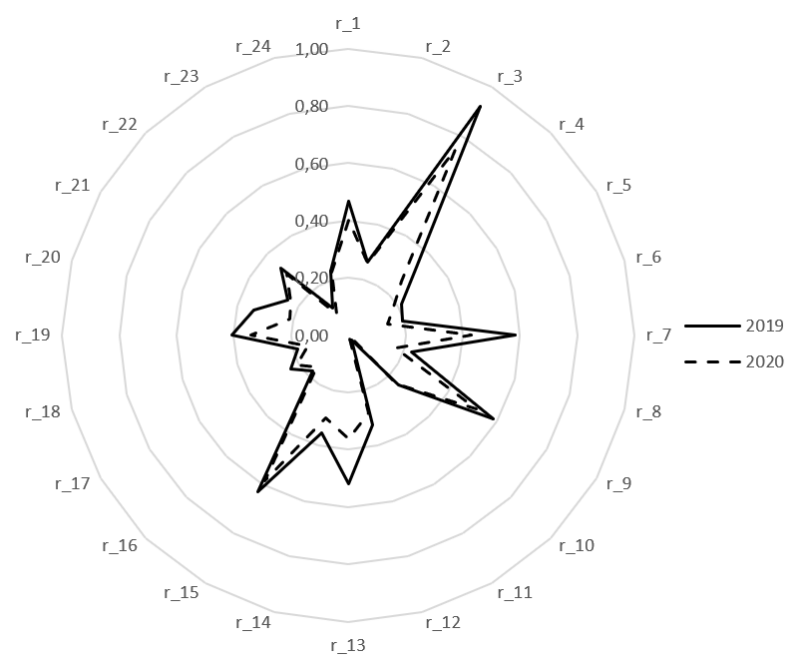

Figure 1: Changing the values of the economic development composite index by regions

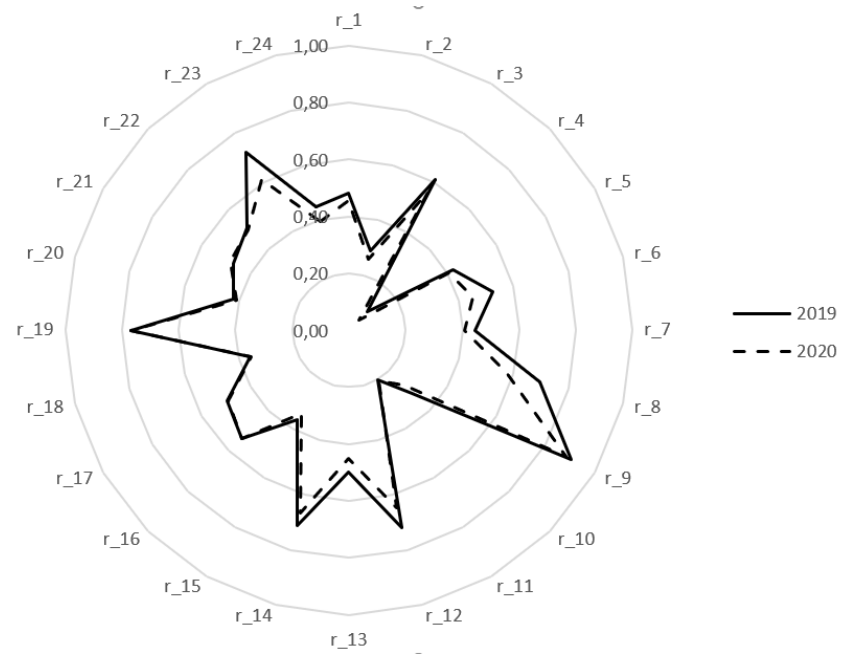


Figure 2: Changing the values of the social development composite index by regions

A comparison of the values of the common composite index for the periods under study (Figure 3) shows a decrease in their values in the first half of 2020. Mostly this decrease is caused by a decrease in indicators that are reflected in economic development.

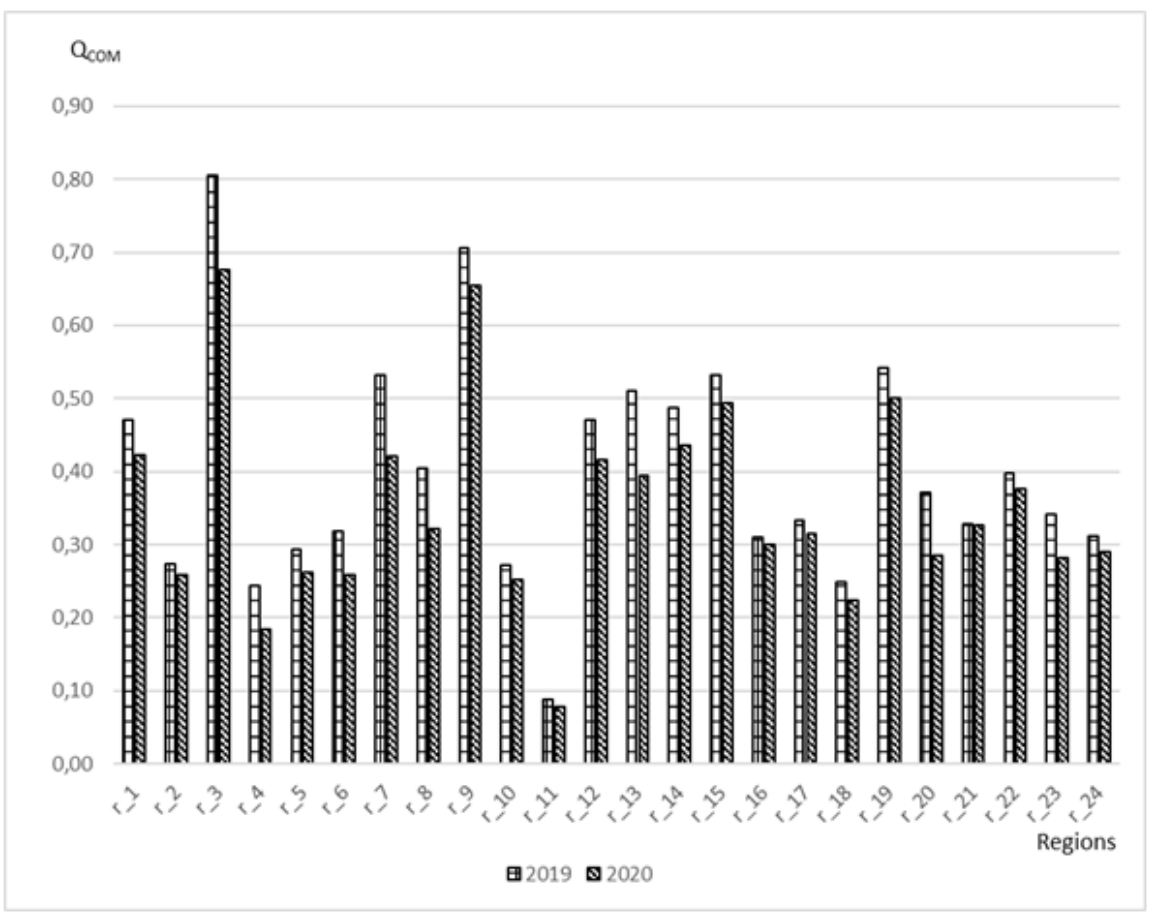

Figure 3: Comparing the values of the common composite index by regions

The greatest reduction of the common composite index value takes place for the Donetsk region (r_4) - by 26 per cent, Zaporizhya region (r_7) - by 24 per cent, Mykolaiv region (r_13) - by 23 per cent, Ivano-Frankivsk (r_8) and Kherson (r_20) regions - by 20 per cent. On average, the reduction of the common composite indicator is 12 per cent. It should be noted that for the Khmelnytskyi region ( $\left.r \_21\right)$ the value of the indicator remained at the same level, for the Rivne region (r_16) the decrease was 3 per cent, Cherkasy region ( $\left.r \_22\right)-5$ per cent, for Sumy region $\left(r \_17\right)-6$ per cent. Note that in these regions in the first half of 2020 there was the lowest in Ukraine incidence of COVID19.

The analysis of the structure of regions in the space of partial composite indices (Figures $4,5)$ shows that in general there were no changes, the grouping of regions in the space of selected indicators remained unchanged.

Four units can be distinguished: Dnipropetrovsk (r_3) and Kyiv (r_9) regions, which have rather high values of indicators, and Donetsk and Luhansk regions ( $r \_4$ and r_11 respectively), where the level of these indices, especially the social development, is quite low. For the rest of the regions, there is a fairly dense grouping, although it should be noted that somewhat separately in this group can be distinguished Poltava (r_15) and 
Kharkiv (r_19) regions.

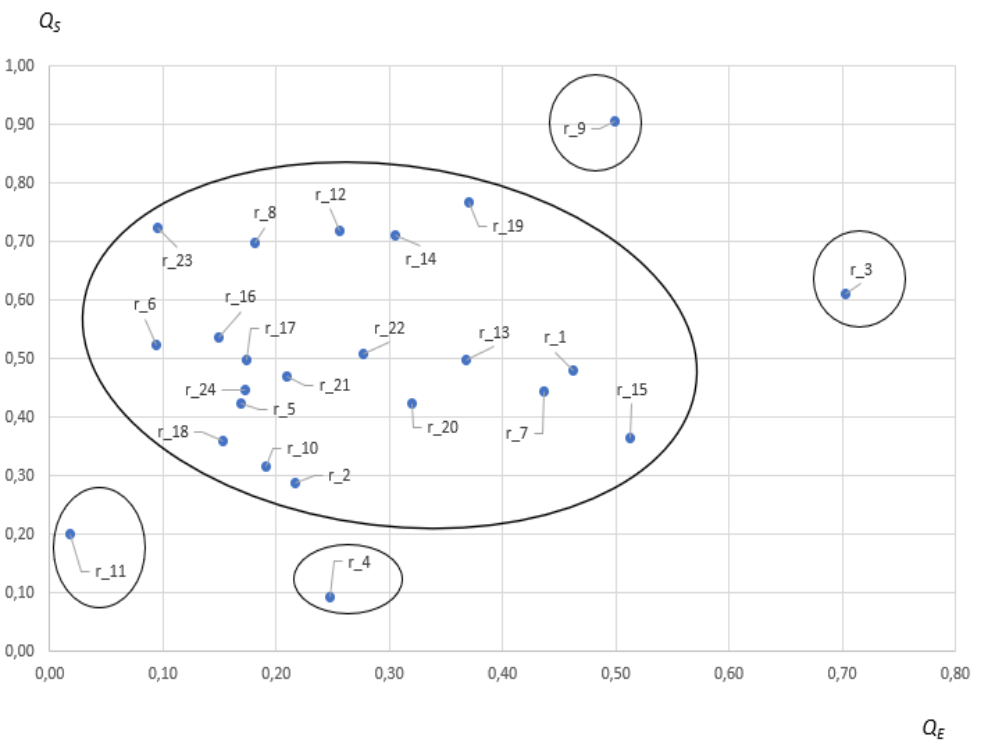

Figure 4. Structure of Ukraine's regions in the space of partial composite indexes for the first half of 2019

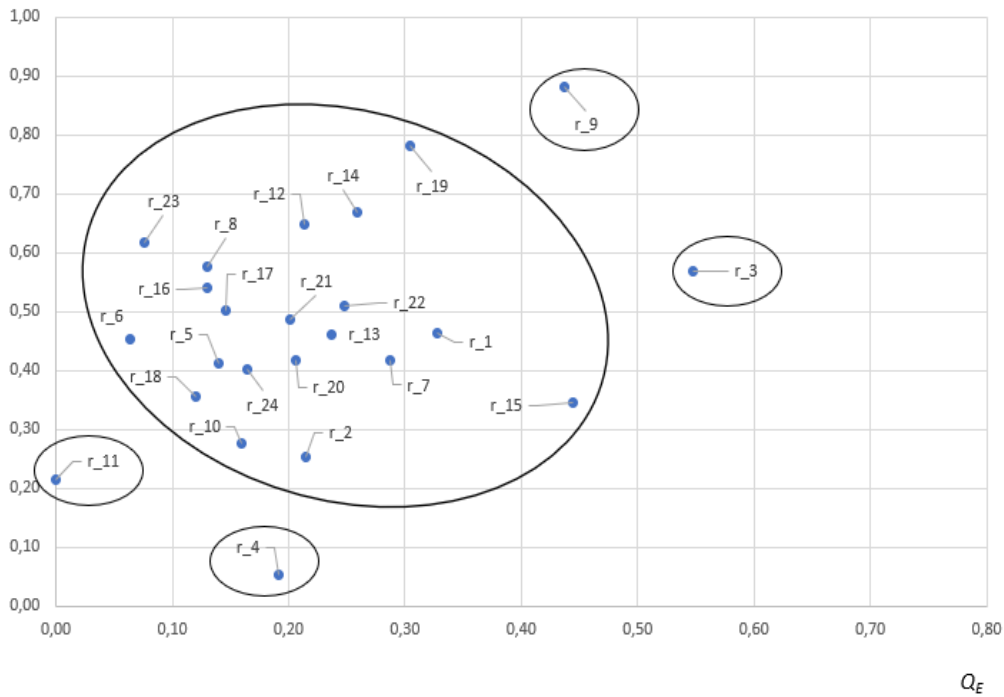

Figure 5. Structure of Ukraine's regions in the space of partial composite indexes for the first half of 2020

Among the factors that continue to harm the socio-economic development of both the country as a whole and individual region, we note the following.

Falling GDP of trading partners causes a reduction in exports of goods. Indirectly, we should also expect a decrease in commodity prices, the share of which at the end of 2019 in domestic exports was 80 per cent. Restrictions on international passenger services, the closure of many European labour markets, and declining demand for exports of services, 
particularly in the IT sector, negatively affect remittances from abroad, which averaged about 8 per cent of GDP annually during 2015-2019, and is an important source of income for Ukrainian households, especially for the western regions of Ukraine. Also due to border closures and quarantine measures abroad, a large number of Ukrainian labor migrants remained in Ukraine who returned to the country at the beginning of the COVID-19 pandemic and did not find decent employment here, which negatively affects the unemployment rate.

Declining demand for goods and services in domestic markets also causes lower production. The decline in agricultural production will be expected, primarily crop production, which, in addition to the negative economic consequences associated with Covid-19, is caused by deteriorating yields due to unusually dry weather in July-August this year.

In times of crisis, international investors usually leave emerging markets, creating a balance of payments crisis and pressure on the local currency. The inflow of foreign direct investment in Ukraine almost stopped at the beginning of the pandemic, and the net outflow of portfolio investment amounted to USD 0.85 billion (Dienkov, 2020). It should also be noted the reduction of international reserves to USD 25.4 billion, or 4.4 months of future imports as of the end of June 2020 (NBU, 2020a).

Ukraine should negotiate further cooperation with the IMF to stabilize its foreign exchange market and create comfortable foreign exchange reserves to be prepared for any emergencies that are caused by the crisis that may occur in the future. Without a support program, the probability of default increases significantly, resulting in inevitable problems and losses.

To neutralize the impact of these negative factors, the government has implemented a number of measures aimed at supporting financial markets, businesses, and individuals. In particular, they are reflected in the adopted regulations, like the State Strategy for Regional Development for 2021-2027 (CMU, 2020), adopted on August 5, 2020, and the State Program of stimulation of the economy to overcome the negative effects caused by restrictive measures to prevent the occurrence and spread of acute respiratory disease COVID-19 caused by coronavirus SARS-CoV-2, for 2020 - 2022 (CMU, 2020b), adopted on May 25, 2020. These documents provide for the implementation of a comprehensive system of new opportunities for stabilization and sustainable development of Ukraine's economy, in particular, through economic incentives for digitalization, development of import substitution of goods and services while maintaining export potential, increasing employment by maintaining existing and stimulating new high-productivity jobs. with decent working conditions. Both monetary and fiscal instruments of influence on economic development are also used. In particular, the National Bank of Ukraine lowered the Key Policy Rate, which is 6 per cent from September 2020 (NBU, 2020b), which should also act as an additional stimulus to economic development, in particular, reduce the cost of lending. The government should also consider financial incentives to support both people and businesses experiencing temporary financial difficulties. The source of such incentives are loans from international financial organizations, even by increasing Ukraine's national debt. 


\section{Conclusions}

Today, Ukraine, like the rest of the world, faces a new challenge - the pandemic of the acute respiratory disease COVID-19, caused by the coronavirus SARS-CoV-2, which forced the introduction of restrictive measures to prevent the spread of COVID19. This negatively affected the activities of the business in all sectors of the economy, foreign economic activity, caused changes in the internal and external environment. The global economy is approaching one of the worst recessions in its history. New trade barriers appear, international investment decreases, the labour movement is limited Forecasts made by both domestic and foreign institutions predict a significant decline in all macroeconomic indicators by the end of 2020. In Ukraine, which has always been more vulnerable to crisis phenomena, the fall in the gross domestic product is projected at 4.8 percent. We propose an approach to the analysis of the impact of COVID-19 on the level and structure of the socio-economic development of the regions of Ukraine, which is based on the use of composite index assessment technology. A set of initial indicators was selected for the study, which was divided according to the content characteristics into a group of indicators of economic development and a group of indicators of social development. The research was conducted according to the data of the first half of 2020 and the same period of 2019. The comparability of the results was also ensured by combining the original data for each indicator for two periods of time into one sample. The corresponding partial composite index was designed for each group. The analysis of the results showed a decrease in the values of the partial composite index of economic development in 2020, which we attribute to the change in business conditions under the influence of the pandemic. For a partial composite index of social development, such changes are not so obvious that can be explained by certain inertia of indicators of employment and unemployment. At the same time, the structural characteristics of the location of regions in the space of partial composite indices remained almost identical. The calculation of the common composite index of socio-economic development also showed negative changes in 2020, which largely depend on the reduction of the values of the partial composite index of economic development, the weight of which in the final result is higher. We considered the measures taken by the Government of Ukraine to neutralize the effects of the pandemic and stabilize the situation, in particular, the government's regional development programs, the measures of the National Bank of Ukraine. The results of the study can be taken into account by public administration as analytical analysis of the situation to shape the regional development strategies. Prospects for further research in this area are to expand the information base for calculations, taking into account indicators of nonmetric nature, in particular, rating data, as well as the inclusion of environmental components. It will allow studying the development of Ukraine's regions from the standpoint of their sustainable development.

\section{References}

Al-Baidhani, A. (2020). COVID-19 Economic Impact on Developed and Developing Economies 2020. Retrieved from https://ssrn.com/abstract=3700352. DOI: http://dx.doi.org/10.2139/ssrn.3700352.

Bloom, D. E. \& Canning, D. (2004) Epidemics and economics: Interactions between global change and human health. Scripta Varia, 106, 304-331. 
Burns, A., Mensbrugghe, D. Van der, Timmer, H. (2006). Evaluating the Economic Consequences of Avian Influenza (Washington, DC, World Bank) Working Paper 47417.

Cavallo, E, Galiani, S, Noy, I \& Pantano, J. (2013). Catastrophic natural disasters and economic growth. Review of Economics and Statistics, 95(5), 1549-61.

CMU. (2020a). Resolution of the Cabinet of Ministers of Ukraine of 05.08.2020 No. 695. On approval of the State Strategy for Regional Development for 2021-2027, Retrieved from https://cutt.ly/nf5qVc4 .

CMU. (2020b). Resolution of the Cabinet of Ministers of Ukraine of 27.05.2020 No. 534. On approval of the State program of economic stimulation to overcome the negative effects caused by restrictive measures to prevent the occurrence and spread of acute respiratory disease COVID-19 caused by coronavirus SARS-CoV-2, for 2020 - 2022. Retrieved from https://cutt.ly/xf5w0cg

De Jongh, J. \& Meyer, D. (2019). The multidimensional regional economic development index (MREDI) applied in the North-West province: a rural regional application. Administratio Publica, 27(3), 162172. Retrieved from https://cutt.ly/Uf5wq33

Dienkov, D., Karakuts, A. \& Shchedrin Y. (2020). Influence of COVID-19 and quarantine restrictions on the economy of Ukraine. Kyiv: Center for Applied Research_Retrieved from https://cutt.ly/rf5wNYL

Estrada. M. A. R. (2020). COVID-19: Economic Recession or Depression. Estudios Económicos, 37(75), 139147. Retrieved from https://cutt.ly/8f5q2oT.

Gallagher, M. (2020). COVID-19 economic impact assessment. Retrieved from https://cutt.ly/Wf5q1ho. DOI: $10.13140 /$ RG.2.2.24484.71042

Gondwe, G. (2020) Assessing the Impact of COVID-19 on Africa's Economic Development. Retrieved from https://cutt.ly/8f5dMKX

Gurna, J. \& Gurna, K. (2015) Analysis of convergence of European regions with the use of composite index. Statistics in Transition New Series, 16(2), 265-278. DOI: https://doi.org/10.21307/stattrans-2015-014.

Hryhoruk, P., Khrushch, N., \& Grygoruk, S. (2019a) An approach to design a composite index of economic development and identifying the bounds of its levels. In: Proceedings of the 2019 9th International Conference on Advanced computer information technologies ASIT'2019 (pp. 48-51). Ceske Budejovice.

Hryhoruk, P., Khrushch, N., \& Grygoruk, S. (2019b). The Rating Model of Ukraine's Regions According to the Level of Economic Development. Periodicals of Engineering and Natural Sciences, 7(2), 712-722. DOI: $10.21533 /$ pen.v7i2.555.g338

Hryhoruk, P., Khrushch, N., \& Grygoruk, S. (2020). Assessment model of regions' economy in the context of their sustainable development. E3S Web of Conferences, 166. paper 13023. Retrieved from https://cutt.ly/Yf5wChA . DOI: https://doi.org/10.1051/e3sconf/202016613023.

IL0. (2020). ILO Monitor: COVID-19 and the world of work. Sixth edition Updated estimates and analysis. Retrieved from https://cutt.ly/kf75SQS .

Jonung, L \& Roeger, W. (2006). The Macroeconomic Effects of a Pandemic in Europe - a Model-Based Assessment. Retrieved from https://cutt.ly/Wf5dVXR. DOI: http://dx.doi.org/10.2139/ssm.920851

Mazziotta, M, \& Pareto, A. A. (2014). Composite index for measuring italian regions' development over time. Rivista Italiana di Economia Demografia e Statistica, LXVIII (3/4), 127-134.

Meyer, D. F. \& De Jongh, J. (20180. An Alternative Multi-Dimensional Regional Economic Development Index: A Provincial Application In South Africa. International Journal of eBusiness and eGovernment Studies, 10(1), 97-113. Retrieved from https://cutt.ly/Hf5q7BR

Meyer, D. F., De Jongh, J. \& Meyer, N. (2016). The Formulation of a Composite Regional Development Index. International Journal of Business and Management Studies, 8(1), 100-116. Retrieved from https://cutt.ly/cf5q8J2

MCTDU. (2020). Rating assessment of regions._Retrieved from https://cutt.ly/The6x2T

NBU. (2020a). Macroeconomic and monetary review. June 2020. Retrieved from https://cutt.ly/Ff5d11H

NBU. (2020b). NBU Key Policy Rate. Retrieved from https://cutt.ly/Jhrr6LU

Nikolaichuk, S., Horshkova, N., Voytenko, V., Khmeliuk, L., Ayvazov, A., Sitnikova, N. \& Mohilat, I. (2020). Ukraine in 2020-2021: Aftermath of the Pandemic. Consensus Forecast. Kyiv: Ministry for Development of Economy, Trade and Agriculture of Ukraine.

Rondinella, T. \& Segre, E. (2014). Index of Quality of Regional Development. In: Michalos A.C. (eds) Encyclopedia of Quality of Life and Well-Being Research. Dordrecht: Springer. DOI: https://doi.org/10.1007/978-94-007-0753-5 3458 . 
Royuela, V. (2020). Construction of a Composite Index of European Identity. Social Indicators Research, 148, 831-861. DOI: https://doi.org/10.1007/s11205-019-02226-5

Stanichkova, M. \& Melecky, L. (2018). Understanding of resilience in the context of regional development using composite index approach: the case of European Union NUTS-2 regions. Regional Studies, Regional Science, 5(1), 231-254. Retrieved from https://cutt.ly/5f5wmMy. DOI: https://doi.org/10.1080/21681376.2018.1470939

State Statistics Service of Ukraine. (2019). Retrieved from http://www.ukrstat.gov.ua/.

State Statistics Service of Ukraine. (2020). News of the State Statistics Service of Ukraine. Retrieved from https://ukrstat.org/

Thomas, M. R., Smith, G., Ferreira, F. H. G., Evans, D., Maliszewska, M., Cruz, M.,...Over, M. (2015). The Economic Impact of Ebola on Sub-Sabaran Africa: Updated Estimates for 2015 (Washington, DC, World Bank) Working Paper 93721.

Ukrinform. (2020). Economic impact of the COVID-19 pandemic on Ukraine. Retrieved from https://cutt.ly/2f5qZ9H

WB. (2020). The Global Economic Outlook During the COVID-19 Pandemic: A Changed World. Retrieved from https://cutt.ly/ff75GUY . 